\title{
A BANALIZAÇÃO DA MENTIRA NA SOCIEDADE CONTEMPORÂNEA E SUA INTERNALIZAÇÃO COMO DESTRUTIVIDADE PSÍQUICA
}

\author{
Angela Caniato \\ Universidade Estadual de Maringá, Maringá, Brasil
}

\begin{abstract}
RESUMO: Na contemporaneidade, a mentira constitui um dos principais atributos das relações sociais, instituindo-se como valor eticamente perverso; manifesta-se como ideologia ou é expressa cinicamente como "mentira manifesta"; a lei é a da hipocrisia normatizada entre os sujeitos; revela-se sob as sutilezas enganosas e opressivas da burocracia, em certas justificativas cínicas de segredo ou de sigilo; destrói as manifestações do desejar, sentir, pensar e agir e esvazia o respeito à alteridade dos indivíduos; apresenta-se potencializada pela cumplicidade, mesmo que inconsciente, dos indivíduos, que a reproduzem em vínculos de farsa. O poder de difusão da mentira sustenta-se na banalização da malignidade que atravessa a vida dos homens. A mentira produz e difunde a atribuição de periculosidade a certos grupos e/ou nações - "os terroristas" - para justificar ações bélicas contra povos com fins prioritariamente econômicos.

PALAVRAS-CHAVE: Mentira; indústria cultural; banalização da malignidade; normatização social; destrutividade psíquica.
\end{abstract}

\section{TRIVIALIZATION OF LIES IN CONTEMPORARY SOCIETY AND THEIR INTERNALIZATION AS PSYCHIC DESTRUCTION}

ABSTRACT: Lies are currently the chief attributes of social relationships with an ethically perverse value. Lies manifest themselves as ideology or are cynically expressed as "overt lies". Naturalized hypocrisy among subjects is the new norm and is revealed beneath the wary and oppressive subtleties of bureaucracy in cynical secrecy or oath justifications. Lies disrupt the manifestations of desire, feeling, thought and activity and blurs the respect towards the individual's alterity. They are totally complicit even though unconsciously individuals reproduce them as a farce. The propagation force of lies is foregrounded in the trivialization of evil that lies within human life. Lies produce and propagate the attribution of dangerousness of certain groups and/or nations, such as that of the so-called "terrorists", so that war activities for economical advantages against certain populations may be justified.

KEYWORDS: Lies; cultural industry; trivialization of wickedness; social standardization; psychic destructibility.

\section{Os Interesses da Sociedade mudam o Significado dos Episódios Culturais}

Há duas gerações, crianças, adolescentes e adultos aguardavam com expectativa e regozijo a chegada do dia 01 de abril - Dia da Mentira - consagrado como tal desde o Século XIII ou XVI (Teixeira, 2002; Universidade Federal de Goiás [UFG], 2004). Era o dia da "brincadeira de enganar o bobo", que, apesar de certo grau de maledicência, trazia consigo o lúdico e a desculpa pelo constrangimento causado ao outro. Nesse dia era permitido trapacear com os amigos, deixá-los assustados e perplexos com notícias picantes, desastrosas e/ou de bons augúrios a fim de vê-los apavorados e/ou hilariantes e nos deliciarmos com seus desconforto e sofrimento, seus tormentos, suas euforias descabidas, deixando-os totalmente vulnerabilizados e impotentes. Eles eram ingenuamente apanhados de surpresa para serem burlados. Eram trapaças contadas como se verdades fossem, para serem logo desmentidas pelo falseador, que se divertia com a credibilidade dada pelo outro à sua mentira. A maledicência mentirosa contra o outro tinha dia permitido para acontecer porque a men- tira era condenada socialmente. O mentiroso contumaz perdia a credibilidade dos demais: a mentira era punida e a verdade premiada.

Presentemente, o dia 01 de abril não tem mais esse glamour, antigamente era uma trapaça inofensiva, uma brincadeira às vezes mais violenta e de mau gosto que permanece, apenas, como ingenuidade na memória daqueles que ainda se esforçam e conseguem viver sob o código da verdade. Na atualidade, ao contrário, todos os dias do ano são dias da mentira, as pessoas estão exageradamente familiarizadas com ela a ponto de poucas quererem saber e viver com a verdade. Esconder a verdade tornou-se forma de exercício de poder, de encobrir, negando, uma sociedade atravessada pela exclusão da maioria: tornou-se ideologia. Tão bem camuflado, esse poderio impregnou a mentalidade coletiva a ponto de muito poucos quererem ouvir o testemunho/interpretação do outro igual que se tornou sem credibilidade - nada lhe teria a dizer, assim como, apenas alguns ousam falar o que pensam por que certamente não encontrariam ouvintes.

De fato os indivíduos estão discriminando e podendo falar/ouvir o que fizeram ou presenciaram? É-lhes permi- 
tido saber o que está ocorrendo em seu entorno, consigo e com os demais homens? O que está acontecendo nessa parafernália de medo de ser verdadeiro, de ser-si-próprio e de conviver na troca e no conflito criador com a diferença do ser-do-outro, com a sua alteridade? Por que a maioria está equalizada/padronizada sob o signo do esconder-se, do enganar e da evitação do contato com a realidade - o mundo do "tô fora"? De fato os indivíduos estão discriminando e podendo falar/ouvir o que fizeram ou presenciaram? É-lhes permitido saber do que está ocorrendo em seu entorno, consigo e com os demais homens?

Esse mentir encoberto ou escancarado, que vem sendo difundido e apreendido de forma banalizada pela sociedade, impede o contato verdadeiro dos indivíduos consigo mesmos e com o mundo que os rodeia e, em especial, proíbe que os homens possam construir um pensamento reflexivo, ao mesmo tempo que priva os indivíduos entre si de vínculos afetivos/desejantes reais - é violência social.

\section{As Relações entre os Indivíduos na Cultura do Enganar}

A verdade parece assustar a quem pudesse assim falar porque a punição culpabilizante de um denunciador real ou fictício o apavora e não faltam sanções sociais para aqueles que ousam dizer o que desejam, sentem e pensam. Ao contrário, a mentira se impõe como um código de conduta, não dito como tal, mas existente de fato na comunicação social, trazendo em seu bojo, por medo ou por alienação, a plena aceitação pelos indivíduos da lógica da hipocrisia, do fingimento e da extorsão do outro. A força do estar escondido, mas cúmplice atuante, propicia a ampla difusão dessa norma de convivência, mesmo porque internalizada inconscientemente por uns, admitida sob coação por outros ou cinicamente consentida por muitos que dela se aproveitam para "levar vantagem em tudo". O poder de infiltração da mentira no âmago da vida dos indivíduos e em suas relações em sociedade, quando transformada em justicativa socialmente aceita, dá a permissão que $u m$ lese o outro sem culpa. Não existe mais a reparação do dano causado a alguém e nem pensar em exigência de retratação pública, se até a palavra desculpa, mesmo que dita falsamente, já caiu em desuso. Há um quase consenso e uma cumplicidade difusa na arte de esconder essa violência simbólica na qual a ofensa e o ludibriar passam a existir até com quem outrora fora amigo. Na mentira, a gratidão e a confiabilidade se perderam como expressão da troca entre os indivíduos. Muitas vezes é o seguro de vida ou o de um bem material que vem substituir as formas de reparar os danos causados a alguém porque ele paga monetariamente os prejuízos causados a outrem.

A fraude disseminou-se como norma social e a dissimulação, o enganar, o ser-impostor articulam a aceitação entre os farsantes, que passam a viver na lógica da adula- ção astuciosa, conduzente à conquista de benefícios oportunistas sob os quais é difícil de alguém escapar: todos se tornam condescendentes com tudo, indiferenciadamente, vivendo sob a hipocrisia. Não existe preocupação ou exigência de busca de discriminação entre mentira e verdade pois o ser verdadeiro vem saindo do cenário da vida entre os homens. $\mathrm{O}$ falsário não se constrange em apontar em si uma virtude que na prática cotidiana ele não exibe. Tudo passa a ser aceito sem julgamento nem hierarquia de valor.

\section{A Moral do Consumo Substituiu a Ética de Valores Humanizadores}

Os indivíduos vivem sob a sedução violentadora e entorpecedora (Lucchesi, 2002) de palavras mentirosas que anestesiam a reflexão crítica, isto é, eles são jogados na onipotência e na ubiqüidade regressivas como se heróis fossem (Caniato, 2000, 2003). Assim atuam porque têm a permissão social para trapacear impunemente o outro e, em nome do lucro, são conduzidos a enganar e a se permitirem ser enganados como aliados fiéis do fraudar o outro e ser enovelados na farsa de si mesmos (Caniato, 1999a). A lei que orienta a vida na sociedade do consumo é a de "enganar o bobo", a qual acaba se tornando uma forma de sobrevivência eivada da violência do desprezo que essa prática contém e que se infiltra nas relações entre os homens, gerando uma cultura na qual prevalece a crueldade disseminada em todas as instituições culturais (Ulloa, 2001a, 2001b).

Nem sempre é possível para os indivíduos identificarem corretamente essa violência como gerada socialmente, mas seus efeitos são vividos por eles que passam a identificá-la como se originária no âmago de seu mundo interno. Essas violências produzidas socialmente são internalizadas e amalgamam-se às estruturas inconscientes dos sujeitos como se fossem próprias à sua agressividade. Dessa forma exercem sua ação destrutiva, agregando-se à consciência moral dos indivíduos como auto-punição (sentimento de culpabilidade) (Freud, 1981). Esse rigor da consciência moral está ele próprio fundado em uma mentira, isto é, em uma inversão ideológica internalizada, que se assenta na culpabilização social, a qual é impingida aos indivíduos desde fora e sob o impacto da impossibilidade de que possam reagir pela ação da mais-repressão que a sociedade impõe às suas agressividades protetoras. Esses mecanismos imobilizam os indivíduos para movimentos de mudança individual e de resistência ao coletivo mentiroso, tornado assim opressor. Transformados em "máscaras mortuárias" (Adorno, 1986a), eles restam paralisados e a possibilidade da solidariedade inexiste, pois a contaminação pelo estereótipo de portadores de malignidade atinge a todos. Os vínculos entre os indivíduos tornam-se perversos, não havendo lugar para o acolhimento nem para a culpa reparatória, porquanto esta exigiria o reconheci- 
mento da importância do outro para mim e a discriminação correta de onde se origina a agressão. A desconfiança conduz a generalizações perversas: todos não são confiáveis.

Estamos vivendo, talvez, preferencialmente, no reino da estranheza e da impossibilidade do aconchego. A disposição psíquica para o acolhimento está sob cerceamento e os vínculos entre os indivíduos estão atravessados por reiteradas separações mutilantes do tipo "ficar com" (Caniato \& Castro, 2002), muitas vezes identificadas positivamente como independência (ou melhor dito, indiferença). $\mathrm{O}$ vínculo continuado vem sendo substituído pelo sofrimento da solidão individualista. O hedonismo prolifera na saturação de prazeres consumistas e cada um, vazio internamente, somente se esfrega no vazio do outro, ambos farsantes do humano (Lipowetsky, 1983). A perda de confiabilidade de um no outro joga todos nessa cultura hedonista, que deixa em cada um a mórbida solidão narcísica (Green, 1988) em um mundo cercado por todos os lados de apelos para as luxurias dos "prazeres consumistas" (Mariotti, 2000). A ilusão da completude cria a utopia do viver sem limites, e a farsa de não dever/poder viver a frustração potencializa a onipotência, que a mentira produz, de caminhar por uma trajetória de expectativas contínuas de satisfação que nunca se realizam (Bauman, 1999). Nem o corpo é poupado e talvez seja nele que a farsa da bioascese se concretize (Ortega, 2002) quando passa a ser usado em rituais coletivos de escarificação ou de suspensão de caráter sadomasoquista. Vã tentativa "bioquímica" de obter prazer na dor (Vieira, 2003), ou melhor, em mais uma busca insana da presentificação do nirvana.

Essa atração pela infinitude torna-se uma força propulsora contagiante de todos os indivíduos, espraiando-se nas relações entre os homens e mantendo-os absortos sob tal engodo. A eficiência desse esvaziamento libidinoso e dessa regressão narcísica torna-se possível sob a sedução da mercadoria que tem um poder tirânico em sua promessa do gozo nirvanesco (Aidé, 2002). Nesse processo relacional entre os homens e a mercadoria, cria-se a ilusão de aceitação incondicional para ludibriar o seduzido. A sedução não só encobre o ultraje do outro, como escamoteia para esse outro o sentimento de ter sido lesado. Ela é um poderoso mecanismo de atrair para privar o outro do que é dele, principalmente, de lesá-lo sem "sofrimento"; de surrupiar dele o que the daria vigor se com ele ficasse - sua força sujeito desejante. O indivíduo sob a sedução deixa de ser autônomo e ilude-se em ser também o outro ao identificar-se, simbioticamente, com aquele que lhe afaga, sob a promessa de possibilitar-lhe prazer pleno (Lucchesi, 2002). Embora lhe reste apenas ser aceito na bajulação, a sedução atinge o auge de seu poder de lesar quando passa a existir o acesso de todos ao mercado, ao reino falacioso das mercadorias - mesmo que seja só nas "lojas de R\$1,99".
Sob o consumismo, o outro é:

tomado por imbecil e serve de expressão ao desrespeito. Entre os pérfidos indivíduos práticos de hoje, a mentira há muito perdeu a sua função de iludir acerca do real. Ninguém acredita em ninguém, todos sabem disto. Só mentimos para dar a entender ao outro que nele nada nos importa, que não temos necessidade dele, que nos é indiferente o que ele pensa de nós. A mentira, antigamente um meio liberal de comunicação, tornou-se hoje uma técnica de descaramento com cujo auxílio cada indivíduo espalha em seu redor a frieza sob cuja proteção ele pode prosperar (Adorno, 1993).

A difusão dessa mentira entre os indivíduos se deve a sua atraência altamente sedutora, que garantiria a cada um a ilusão de uma certa onipotência justamente porque atua no nível da produção inconsciente de falsos desejos. Doce ilusão! A captura consumista dos desejos humanos é uma poderosa estratégia de dominação a que os indivíduos se deixam entregar sem oferecer resistência ao invasor. Ao contrário de uma autonomia verdadeira, ela gera e mantém os indivíduos amalgamados entre si sob o comando da mercadoria e do engodo de serem os melhores. A sedução mercadológica atua como um poderoso fomentador dessa mentira e impede que a verdade da falácia ou da privação possa se tornar o guia de resistências sociais. A sociedade precisa se manter sob a lei do lucro e é necessário escamotear a verdade do acesso seletivo/excludente, de fato, aos bens produzidos socialmente. Mais ainda, não pode sequer ser vislumbrada a substituição destrutiva dos objetos do desejo humano pela presença/ausência dos objetos de consumo que resplandecem lambuzados de perfídia edulcorada (Caniato, 2003). Aliás, como diz Lucchesi (2002):

a palavra sedução vem do latim seducere (se[d] +ducere), sendo que sed significa 'separação', 'afastamento', 'privação' e ducere queria dizer 'levar', 'guiar', 'atrair'. Em síntese, portanto, 'seduzir' era o processo pelo qual se atrai para privar o outro da autonomia de si, sob a promessa de possibilitar-lhe a experiência do prazer pleno. (p. 1).

As mentiras, na contemporaneidade, são poderosas estratégias usadas de forma mais ou menos intencional pela sociedade da mercadoria para poder vender os seus produtos. Eles são apresentados de forma sedutora glamourizada - sob a promessa de prazer sem limites, para despertar a cobiça de compra, mas com o cuidado de ocultar as intenções de logro dos que devem ser capturados como consumidores vorazes. A mídia tornou-se o principal orquestrador dessa máquina com a tarefa de representar, junto às populações, os poderes instituídos pela lógica da mercadoria. Ela exerce a grande função "educativa" de construir mentalidades que sustentem esse status $q u o$, isto é, cria e difunde massivamente os modelos iden- 
tificatórios exigidos pela organização social. Sem nenhum pudor, seus agentes transformam os indivíduos em consumidores por excelência, tornando-se os porta-vozes dessa mentira esvaziadora do ser pessoa. Esse poderoso instrumento de manipulação social é nomeado por Adorno (1995) como indústria cultural, tendo na ideologia o seu suporte de eficiência. Isto porque, como diz Cohn (1986):

A ideologia além de ser um processo formador da consciência e não apenas instalado nela, opera no nível do inconsciente no sentido forte do termo: ela não apenas oculta os dados da realidade mas os reprime, deixando-os sempre prontos a retornar à consciência, ainda que de novo sob formas ideológicas. Nessas condições, o desenvolvimento da consciência pelo contato reflexivo com a realidade é um processo doloroso, como o é a própria civilização na concepção freudiana. Trata-se de um processo difícil de ser suportado por pessoas cuja estrutura de personalidade foi moldada para reproduzir a heteronomia e fugir do esforço de defrontar-se com a diferença e o novo. (p. 17, grifos nossos).

Além do mais, sob o esconderijo da ideologia, as informações são omitidas, insuficientes ou truncadas; portanto a atividade relacional da consciência de apreensão sensitiva-perceptiva-intelectual não pode se efetuar, e a representação simbólica do objeto é feita de forma deformada. Essa privação de informação que integra a mentira é, para Nilo Odália (1983), a fundamental característica da violência.

Chegamos, portanto, ao ponto crucial para a compreensão da relação cultura e subjetividade, pois é a indústria cultural que mediatiza essa relação e, em especial, o faz por meio dos modelos identificatórios por ela produzidos, portadores das representações ideológicas internalizadas pelos indivíduos. A indústria cultural é uma fábrica intencional e perversa de mentira integrada à sua dimensão ideológica que contém ofalseamento da realidade objetiva com a intenção de produzir individualidades modeladas para a sustentação do status quo. Enganosa e destrutiva, porque encobre o foco da verdade, retirando do indivíduo a possibilidade de captura, pela consciência, do real existente quando escamoteia e omite dados objetivos. A capacidade de discernimento, julgamento e decisão da consciência humana é afastada do foco de apreensão dos objetos, ficando inativa, deixando os indivíduos expostos à manipulação social. $\mathrm{O}$ vínculo entre o indivíduo e a cultura, mediatizado pela ideologia, põe em contato direto o inconsciente com a irracionalidade da ideologia, driblando a consciência e seus componentes cognitivosracionais, conseqüentemente, mantendo os indivíduos sob funcionamento mental regressivo. A mídia é o principal instrumento da indústria cultural, que, com seu grande poder de difusão e o uso massivo da sedução, torna assimilável por todos o poder violentador da ideologia, isto é, sua força produtora da padronização de todos, vinculados simbiótica e indifenciadamente entre si (Caniato, 1999b).

Sabemos que esse mecanismo de internalização inconsciente dos modelos identificatórios propostos socialmente produz uma espécie de fusão simbiótica entre os indivíduos, mas que lhes dá a sensação de que suas formas de ser são autóctones, de cada um, mesmo quando se vêem refletidos nesse "espelho" narcisicamente nefasto. São naturalizadas as formas de desejar, sentir, pensar e agir, porque imbricadas no "estilo de vida", que,entretanto, é produzido socialmente para a manipulação. $\mathrm{O}$ mais agravante é que esses modelos identificatórios internalizados transitam livremente como verdades para os indivíduos e nas relações entre eles. Não se tornam detectáveis conscientemente os processos de identificação projetiva e introjetiva que produzem a não-diferenciação entre os indivíduos: o suposto "indivíduo rei" do individualismo contemporâneo é ele mesmo uma farsa, uma mentira, um "pseudo-indivíduo" na designação de Theodor Adorno.

\section{A (Des)Construção Subjetiva}

sob a Saraivada de Relações Enganosas

Destarte, mais ou menos manifestas, as mentiras vêm sendo internalizadas e sustentadas pelos indivíduos que assim se tornam cúmplices dos desvarios que atravessam o dia-a-dia da vida em sociedade. A pseudo-verdade difundida é acolhida no âmbito da irracionalidade mental e dos afetos contaminados pela indiferenciação/inversão que o mundo atual impõe aos sentimentos relacionais e à angústia dos indivíduos (Maia, 2001). A captura social da afetividade dos indivíduos é uma poderosa estratégia manipulativa (Arendt, 2002), intencionalmente produzida para gerar confusões conceituais, que vêm a se articular de forma complacente com as consciências já deterioradas regressivamente.

Há de se considerar que uma das expressões da mentira manifesta-se como omissão/falseamento de informação que atinge de forma prejudicial a capacidade de representação da consciência humana. Nãoé possível haver uma apreensão real e verdadeira de determinado objeto se não estiverem expostos ao exame sensório-perceptivo-intelectual todos os elementos que o integram. Sob o esconderijo da ideologia da indústria cultural, isso não ocorre, visto que as informações são omitidas, insuficientes ou truncadas, portanto a atividade relacional da apreensão perceptivointelectual não se efetua e a representação simbólica do objeto é feita de forma deformada.

Com a afetividade humana ocorrem prejuízos similares, ocasionados pelas deformações dos significados dos afetos que deixam de sinalizar corretamente as diferentes nuances discriminatórias presentes nas relações. Os indivíduos ficam fragilizados, atordoados, mesmo, para a identificação e discriminação do ataque ou do aconchego, do 
amigo ou do inimigo, da traição ou da sinceridade, da agressividade da inveja ou do afago amistoso; portanto, expostos às manipulações de uma sociedade muito pouco preocupada com os caminhos dos sentimentos humanos dos homens: a vulnerabilidade humana é explorada em todas as suas determinações.

Por outro lado, os homens necessitam conservar íntegros os seus afetos a fim de que possam expressá-los para se orientar de forma criativa, isto é, dando significados diferenciadores às situações vividas. Se individualizados, sentimentos e emoções seriam colocados a seu serviço, integrando-se à consciência, na qual recebem as representações que irão lhe disponibilizar a narrativa dos episódios do dia a dia. Nessa perspectiva, aos indivíduos seria permitida a diferenciação das situações vivenciadas e eles tornar-se-iam capazes de identificar e reagir diferentemente às distintas situações que a vida cotidiana lhes propõe. A mentira não lhes retiraria a discriminação entre o que lhes faz bem e o que lhes faz mal. Isso só ocorre quando os indivíduos podem usar os indicadores diferenciadores de sua vida afetiva dessa forma criativa e conscientemente integradora. Na contemporaneidade, a expressão dos sentimentos está sob condenação social e, infelizmente, assim vivida pelos indivíduos que vêm se permitindo lhes deixar serem subtraídas essas suas potencialidades diferenciadoras. A linguagem significante dos afetos está corrompida: "é obsceno falar de amor" (Stengel, 2003), tal como é proibido sentir o medo protetor que nos aponta os perigos a serem evitados ou enfrentados, assim como as vivências de perda e dor devem ser sedadas por drogas legais ou ilícitas. A palavra de ordem é a seguinte: não pode haver quebras no afã instantaneista de um prazer sem interrupção no qual a euforia não deve nunca terminar - é proibido ficar triste (Di Loretto, 1997). No entanto, os afetos não estão mortos, mas sim capturados e sob manipulação do mundo da primazia da mercadoria, sob a exploração e exclusão sociais que os homens estão vivendo sob o “capitalismo flexível” (Sennett, 2001). Nele, não existe compromisso com a sobrevivência dos indivíduos que estão compelidos/exigidos para performances que ultrapassam as suas reais possibilidades humanas (Barbarini, 2001) e submetidos, portanto, a viverem sob o manto acobertador e mentiroso da negação desse sofrimento (Dejours, 2000).

O homem não é o ser impotente em que a sociedade o quer transformar, nem o herói que ela lhe outorga ser como substituições do vital que dele retira. É possível aos indivíduos acolher os apelos de vida que brotam de seus desejos e afetos e se valer deles para abandonar o trono no Olimpo no qual vêm sendo obrigados a sentarem. No reino da sabedoria, a humildade e a finitude falam da possibilidade de o homem de nunca se considerar completo e permanecer ativo na procura de novas descobertas a respeito de si e do mundo que o cerca. Afinal, até onde ele poderá continuar vivendo sob o intenso "prazer" do mundo, da luxuria, no qual the são expropriados seus desejos e afetos, canalizados de forma sorrateira para os objetos de consumo (Mariotti, 2000)? As promessas são nirvanescas e as tentações demoníacas para uma vida sem limite. Como abandonar as promessas falaciosas desse mundo tentador? Não é fácil desligar-se da onipotência de um inconsciente desejante que fustiga desde dentro para o gozo perene exigido pelo "sentimento oceânico" (Freud, 1948). É essa a força propulsora em que se apóia a sociedade atual, o que se torna o perigoso, pois a insatisfação insaciável não vem servindo de freio para a procura de um gozo mais seguro. A pressão social para que isso não ocorra é muito forte e a tentação dos prazeres sem limites é altamente instigante. Contudo alguns homens e grupos já vêm conseguindo libertar-se desses impedimentos que aprisionam a sua autonomia e integridade subjetivas. Certamente é possível o homem liberar-se das falsas promessas do consumismo, retomar as rédeas de sujeito da cultura e caminhar com os seus parceiros na busca de novas formas de vida. ${ }^{1}$ Quando? Oxalá seja em breve.

$\mathrm{O}$ indivíduo sozinho não consegue mudar esse rumo e precisa do anteparo do outro que o acolha/frustre, que com sua presença lhe dê o sentido de limite e a firmeza da autoridade para continuar. Todos e cada um não podem abrir mão da irreversibilidade da dependência do outro humano, que é tão frágil como eu sou e que precisa do meu afago para que eu e ele saiamos do esconderijo "protetor" da simbiose que nos faz sofrer, ao nos conduzir à assimilação do ethos cultural da contemporaneidade: "vazio" na saturação de prazeres tal como defende Lipowetsky (1983) ou na falácia de um "estilo de vida" tal como proposto por Lowen (1983). A cultura contemporânea não vem dando referenciais protetores ao humano dos homens. Inexiste um ethos caloroso por meio do qual um pudesse debruçar-se sobre o outro em um enlace prazeroso, verdadeiramente humanizador, sob as diferentes nuances em que o amor pode se desdobrar (sublimação, enamoramento, ternura, acolhimento,fraternidade, solidariedade), saída da onipotência narcísica primitiva, do respeito à alteridade e a diferença entre os indivíduos.

A análise da relação entre subjetividade e cultura que está sendo desenvolvida neste texto está respaldada na abordagem psicopolítica de Theodor Adorno, que articula os elementos constitutivos do psiquismo propostos por Freud, a partir de uma perspectiva dialética de relação de cumplicidade entre o indivíduo e o social. Ao entender que leis distintas regem esses dois níveis da vida dos homens subjetividade e cultura -, torna-se enriquecedor detectar e analisar os liames que integram essas duas instâncias psicossocial - do ser humano e verificar nelas as suas interpenetrabilidades, sem desconhecer suas especificidades 
diferenciadoras. Isso significa dizer não lidar com a subjetividade como se ela fosse uma mônada, nem com a sociedade desconhecendo que ela é construída por sujeitos humanos. A ignorância dessa relação muitas vezes resulta em teorias e práticas que sustentam a onipotência individual e/ou acusam/culpabilizam/patologizam o indivíduo, violentando-o mais ainda, tão a gosto da manutenção das mentiras da sociedade contemporânea. Dizendo de forma mais simples: não psicologizar o social nem sociologizar o psíquico.

Essa abordagem da relação subjetividade-cultura proposta por Adorno em sua monumental pesquisa "A Personalidade Autoritária" e seus fundamentos estão sendo usados neste texto como base para analisarmos os tipos de "pseudo-indivíduos" que dão adesão ao arbítrio, porque destruídos internamente (máscara mortuária) e por terem a consciência fragilizada e regredida. Na contemporaneidade, a forma consumista de existir contém o germe do autoritarismo do mercado, na qual a arbitrariedade da violência se expressa de forma camuflada; ela exige a adesão mais ou menos consciente dos indivíduos para poder se manter.Éa cumplicidade subjetiva que vem sustentando tanto as formas de violência dos genocídios - tal como nas guerras - ou a violência simbólica escamoteada da vociferação ideológica acolhida/mantida pelos consumidores. A essa relação, Adorno (1986a), em seu texto "Indústria Cultural", designa como sociabilidade autoritária:

A idéia de que o mundo quer ser enganado tornou-se mais verdadeira do que, sem dúvida, jamais pretendeu ser. Não somente os homens caem no logro, como se diz, desde que isso lhe dê uma satisfação por mais fugaz que seja, como também desejam essa impostura que eles próprios entrevêem; esforçam-se por fecharem os olhos e aprovam, numa espécie de autodesprezo, aquilo que lhes ocorre e do qual sabem por que é fabricado. Sem o confessar, pressentem que suas vidas se lhes tornam intoleráveis tão logo não mais se agarrem a satisfações que na realidade, não o são. (p. 96, itálicos nossos).

Portanto, essas mentiras sob as quais vivemos do que é ser homem e todas as promessas vãs que elas contém trazem em seu bojo distorções difíceis - mas não impossíveis - de serem desveladas por uma ciência como a Psicanálise, se a abordagem de "visão de avestruz" (Caniato, 1999b) não prevalecer, se não forem desconsideradas as afirmativas categóricas de Freud da dimensão social do psiquismo, espalhada em várias de suas obras e, de forma mais concentrada, naquelas consideradas de caráter social como Psicologia de las masas (1948) e El malestar en la cultura (1981). A prática na Psicanálise que se mantiver intimista, negando a heteronomia na estruturação das subjetividades, além de jogar seus clientes-vítimas na violência da culpabilidade (Freud, 1981), estará sendo cúmplice de uma cultura falaciosa, hipócrita, mentirosa e perversa, portanto de um sofrimento dos homens socialmente produzido. Já chegam os marqueteiros da mídia que dominam muito bem o conhecimento psicanalítico e nele se apóiam para melhor manipular os indivíduos incautos e desatenciosos, talvez uma grande maioria, tendo em vista o poder cada vez maior de penetração dos meios de difusão de massa, ao qual Guinsberg (2001) se refere.

Como colaborar para minimizar a ação da mentira facilmente internalizável pelos indivíduos e de efeitos tão perversamente destrutivos nas suas vidas psíquicas como estamos podendo entender? Pior ainda: quando sabemos que a mentira vem ultrapassando o nível da palavra falada/ ouvida, quando seus atributos irracionais e perversos vêm desembocando em atitudes disruptivas concretas e observáveis dos indivíduos em suas relações com os demais? Certamente é uma questão desafiadora para nós, os profissionais da Psicologia, que vivemos intensamente esses sofrimentos na prática cotidiana. Talvez devamos pensar um pouco mais de forma contextual, procurando desvelar os significados dos meandros enganosos do status quo no qual vivemos. Enfim, quais os valores sócio-morais que desvirtuam e pervertem as relações afetivas entre os homens na cultura atual, para não mais jogarmos nossos clientes na destrutividade de um "se seu marido lhe traiu, o traia também" (sic). Banalização desrespeitosa e violentadora de dois dos sentimentos mais dolorosos e importantes que envolvem o ser traído: a inveja e o ciúme (Arreguy \& Garcia, 2002; Ventura, 1998).

Continuemos pensando: se os afetos não estão integrados à clareza diferenciadora que a consciência lhes pode oferecer, isto é, se o cotidiano está sendo vivido sob restrições da afetividade, facilmente os homens caem nas falsificações sob as quais as mentiras florescem, em especial, não esqueçamos, porque respaldadas por sua transformação em norma social. Quando são internalizadas pela consciência moral de cada um e sancionadas pelas mentes individuais do grupo circundante, passam a ser percebidas e identificadas como originárias do mundo interno dos sujeitos, portanto naturalizadas. Se um do grupo começa a duvidar desses valores, quando vislumbra alternativas outras que não sejam as apresentadas pelo status quo mentiroso e, quando tenta viver diferente, é chamado de "careta" e tem o descrédito dos demais. De fato, alguns estão satisfeitos porque estão lucrando com essa forma de vida e outros, infelizes e insatisfeitos porquanto estão sofrendo, mas calados. Por que não conseguem trazer para si e seu grupo a tarefa de mudar, de sair da farsa de que são "homens felizes"? Por que continuar seguindo essa forma de vida em bando, turba e até mesmo em gangue (Pagman, Simionato \& Mena, 2003), deixando que suas leis destrutivas reinem soberanas e enganando-se como estando “felizes/entorpecidos/drogados”? Não há dúvidas de que 
a dificuldade mais significativa é que tal inversão é de caráter ideológico - indústria cultural - , mas que quando internalizada pelos indivíduos, é decodificada por eles como se próprias fossem, autóctones.

Desse modo, vai-se evidenciando que são profundas as implicações no mundo interno dos sujeitos da perversidade das mentiras na sociedade contemporânea. Fica difundida uma espécie de cultura cujas relações constroem a pseudo-individuação e estandardização do coletivo (Adorno, 1986a; Adorno \& Horkheimer, 1985). A ilusão do individualismo de um indivíduo livre e independente logo esbarra nas amarras da equalização autoritária que, de algum modo, emaranha e ata os indivíduos uns aos outros numa teia de relações na qual o modus vivendi é o de promessas vãs de felicidade/mentiras. O vínculo interrelacional é, portanto, o do narcisismo de morte de que nos fala Green (1988)

\section{A Predominância nas Relações Sociais do Caos e do Horror Camuflados}

Nesse momento, cabem algumas indagações intrigantes quando nos defrontamos com os estragos nas relações sociais, em que a perda da credibilidade em si e no outro difunde entre os indivíduos. São inúmeras as dificuldades que se interpõem no trânsito entre eles dos seus impulsos desejantes, sentimentos e pensamentos para que possam ser, para todos, referenciais factíveis de discriminação, de julgamento, de avaliação e de decisão de formas seguras para cada um e todos na orientação de suas vidas individuais/coletivas, enquanto sujeitos da cultura. É possível, nesse contexto, que uma consciência crítica desenvolva-se, que os indivíduos ascendam à autonomia exigida para as suas emancipações enquanto sujeitos da cultura, para que eles se tornem verdadeiramente sujeitos sociais? (Adorno, 1986a; Adorno \& Horkheimer, 1985).

Como analisamos previamente, do ponto de vista político-cultural, a ordenação social gerada sob o signo das mentiras da sociedade da mercadoria vem produzindo diferentes formas de confusão na organização da vida entre os homens. Torna-se difícil, senão impossível, identificar o certo e o errado que permitiria a discriminação protetora pelos indivíduos que, ao contrário, passam a seguir cegamente os demais sem identificar corretamente a presença/ausência de riscos e perigos, que teriam de ser enfrentados de maneiras distintas.

Ao semear o engano entre os indivíduos, a mentira retira-lhes a possibilidade de discernir o que e a quem obedecer (Dufour, 2001), entre o sabotador e aquele que lhes possa, de fato, garantir uma autoridade protetora, sob a qual possa viver uma disciplina reguladora do coletivo que lhes forneça referenciais de efetivo amparo (Lipowetsky, 1983). O clima angustiante de alerta tornou-se permanente no dia a dia dos homens, iluminado pelas luzes fulgurantes de poderosos foguetes e mísseis, que explo- dem ao atingir seus alvos humanos. Esses espetáculos inusitados (Kehl, 2002), de beleza estupefaciente, são trazidos pela mídia para dentro das casas das pessoas, simulacro "esplendoroso de fogos de artifício", que encantam ao invés de horrorizar. Embora sob tal opulência e sob a distância (Bauman, 1998a), que a virtualidade da mídia propicia, é essa uma expressão do holocausto atual, um fato verdadeiro de mortandade coletiva. Porém, parece ser melhor permanecer sob o engano e acalentar-se negando o real, ficar com o espetáculo luminoso fulgurante e admiti-lo apenas como virtual. Negar/enganar-se/mentir para si próprio que os homens não estão sendo mortos é melhor do que viver sob a ameaça de tantos "sibilos venenosos"!! (Polo, 2004).

Em seu limite de ocultamento da verdade, a mentira funciona como segredo (Arendt, 1973) e essa é uma das maneiras dos países ricos e poderosos beneficiarem-se para a manutenção de suas hegemonias econômico-política, inclusive sob o domínio absoluto e quase que exclusivo das tecnologias de guerra. Sabido é o empenho dos Estados Unidos em utilizar, sorrateiramente, seu poder junto a entidades internacionais, para lhes garantir a palavra final em questões de interesses mundiais, mesmo que sob o prejuízo de muitos e muitos povos. Essa imposição arbitrária de poder fica escondida, assim como são camufladas as ações bélicas que são justificadas como de combate ao terrorismo (Kornbluh, 2004; Pilger, 2004; Quesada, 2004) e ao narcotráfico, quando já é conhecido que esse país retira volumoso lucro da preparação e do comércio de drogas (Beinstein, 2000; Brie, 2000a, 2000b). A sociedade mundial globalizada está assentada em múltiplas formas de opressão que às vezes se revelam como aviltante cinismo contra os despossuídos. Se não é a iminência de conflitos bélicos, é a explosão de violência entre grupos políticos-raciais antagônicos ou mesmo a violência da miséria em contraste com a opulência da riqueza de poucos que constrange aos que ainda conservam alguma capacidade de indignação. Em qualquer lugar do mundo não se está seguro, e ameaça de uma "explosão criminosa", inclusive de natureza nuclear, acompanha a todos, sem que se possa saber se é real a ameaça ou se é mais uma estratégia maquiavélica de produção do horror como vem sendo corriqueiro - para deixar as pessoas atônitas e paralisadas. A supremacia da lógica do dinheiro atravessa todas as nações e os homens no mundo estão atrelados a essa,sim, verdadeira rede terrorífica de defesa do lucro, na qual sobra pouco espaço para o humano dos homens (M. F. Castro, 2004 [comunicação pessoal] 21 de abril de 2004). Sob esse emaranhado dissimulado da caça ao dinheiro, efetiva-se a imobilização de homens aparvalhados que, assim enganados, se deixam levar pelo arbítrio do poder instituído para serem melhor controlados, domesticados em nome de um simulacro de proteção social: vigilância e segurança (Caniato \& Nascimento, 2006). 
Podem-se constatar o clima de suspeição generalizada entre os homens, a exigência de vigilância sobre quem possa burlar essas normas (Abeche, 2003; Caniato \& Nascimento, 2006) e a expectativa de poder morrer se for tido como terrorista (Chomsky, 2002). O embuste na sociedade transforma-se na criminalização dos homens (M. F. Castro, 2004 [comunicação pessoal] 21 de abril de 2004; Ciombra, 2001) que estão vivendo/sofrendo na contemporaneidade por, além de pobres e excluídos, serem identificados sob a estereotipia de perigosos. Quem os respeita? Por quem podem ser acreditáveis? Será que só lhes resta o caminho da contravenção das drogas e do crime? Onde buscar vínculos confiáveis que lhes possam prover referenciais de autoridade para lhes garantir uma direção segura (modelo identificatório de ego ideal)? Será que ainda não existem condições objetivas que permitam aos indivíduos chegar a uma clareza de pensamento tal que lhes aponte para onde precisam conduzir as suas vidas e assim poderem se organizar a fim de reverter esse quadro de mórbida passividade? Permanecem cada um e todos nos porões obscuros e regredidos dessa violência cruel internalizada que funciona como impedimento/proibição de testemunhar no diálogo com o outro a sua potência para elevar-se a um pensamento crítico conduzente e a atitudes sujeitoemancipatórias (Adorno, 1995). Muito ao contrário, expostos e fragilizados sob esse caótico espaço cultural, a fragmentação coletiva construída é a da apatia e do conformismo (Chauí, 1993; Martín-Baró, 1987), sob o qual os indivíduos se tornam cúmplices em uma solidão mórbida e, apenas, vinculados pelo ódio elou pelo "prazer em lamber as próprias feridas".

Dizendo de outra maneira, os indivíduos, quando enrustidos nessa não-reação, porque amalgamados de forma mais ou menos consciente nessa "mórbida semelhança", encaram a hostilidade vivida como sendo natural: é o que Hannah Arendt (2000) designa como "banalidade do mal”. A essa banalização agregam-se outras, como ocorre com a "banalização da injustiça social”. As quais vão se amalgamando no mundo interno dos já tornados pseudoindivíduos, potencializando seus atributos corrosivos quando eles atribuem tal descalabro a si próprios. No entender de Dejours (2000), os indivíduos, culpabilizandose por esses desastres, tornam-se normopatas tal o grau de insensibilidade e negação do sofrimento que desenvolvem. O nível de degradação subjetiva pode chegar ao ponto em que os parâmetros do ser feliz e/ou do sofrer não mais estão separados e discriminados para poderem ser vividos diferentemente pelos indivíduos, confundidos pela "banalização da dor e do sofrimento" (Caniato, 2003). Ao negarem seus próprios sofrimentos pelo seu silenciamento, tornam-se insensíveis à dor alheia.

A grande maioria engana-se, não conseguindo perceber essa inversão perversa do lócus da violência social, porque vive sob a impossibilidade de usar a agressividade como proteção à vida (integração de libido e thânatos) as pessoas são obrigadas a "amar ao próximo como a si mesmo" (Freud, 1981) e agüentar caladas serem violentadas e, como em um festim coletivo de auto-mutilação, mantêm-se sob:

... a elogiada têmpera para a qual se é educado. Significa pura e simplesmente a indiferença à dor. Aquele que é duro contra si mesmo adquire o direito de sê-lo contra os demais $e$ se vinga da dor que não teve a liberdade de demonstrar que precisou reprimir. Esse mecanismo deve ser conscientizado, da mesma forma que deve ser fomentada uma educação que não mais premie a dor e a capacidade de suportá-la (Adorno, 1986b, p. 39).

Essa espécie de cinismo mórbido consigo próprio que identificamos facilmente em indivíduos e grupos das classes pauperizadas, que vivem sob a extrema penúria da exclusão social, fica claramente evidenciável nas expressões psicossociais dos indivíduos em geral em momentos de maior autoritarismo social pela impregnante/adesão, mesmo que inconsciente, às atribuições de malignidade que lhes são imputadas. Quanto mais exuberantes e clamorosos forem tais apelos, mais evidenciável será essa hostilidade nas atitudes dos indivíduos. Reportando-se à ordenação autoritária produzida pelo fascismo e à adesão dos indivíduos à vociferação do grande tirano, Iray Carone (2004) expressa:

... os discursos de Hitler não escondiam os seus objetivos de dominação, de um lado, e de intenção de extermínio dos judeus, de outro. Objetivos e intenções que foram, a despeito de seu completo irracionalismo, aceitos pelas massas, inclusive a proletária. Pela primeira vez na história a ideologia não apareceu sob camuflagem de interesses totalitários, mas como 'mentira manifesta'. A ideologia fascista foi, como disse Adorno, 'involuntariamente sincera' ( $\mathrm{p}$. 36, grifos nossos).

\section{A Ampliação da Malignidade \\ da Mentira sob o Poder do Dinheiro}

Enquanto o consumismo continua angariando mais e mais adeptos e distraindo as pessoas para distanciá-las das suas próprias vidas, no novo modelo político neoliberal, o ápice da direção da sociedade está nas mãos do capital financeiro e permanece funcionando sob o que dizem ser democracia, embora ainda estejam outorgados aos Estados os poderes e as funções do executivo, do legislativo e do judiciário. No entanto, o Estado não mais realiza a mediação da relação capital - trabalho, mas, sim, o controle está totalmente subsumido aos agentes financeiros e às grandes corporações industriais. Ao ter-se tornado, apenas, apêndice desse “capitalismo flexível", o Estado vem levando em derrocada os indivíduos-cidadãos, intensificando-se os sofrimentos da exclusão social que são 
atenuados pela “indústria do entretenimento”, a grande máquina da mentira na contemporaneidade (Martin \& Schumann, 1999). A fábrica, isto é, a produção de mercadorias, está à matroca do mercado, seguindo as demandas de consumo sempre renováveis (toyotismo). O trabalhador fica à mercê da super competição e, para garantir seu emprego, é-lhe exigido ter competências sempre mutáveis, vivendo sob alto nível de exigências de performance ser herói-e, necessariamente, tendo de suportar muito sofrimento para manter o emprego (Barbarini, 2001).

Todavia essa parafernália de opressão é invisível, escamoteada, acobertada pela culpabilização individual de cada trabalhador quando ele vislumbra, embaçadamente, o sofrimento e prenuncia a possibilidade de queixar-se para, em seguida, mergulhar nas malhas poderosas do silêncio de sua própria dor - mentir a respeito de si, como exprime Hannah Arendt (2002), de forma categórica e trágica, ao examinar a inconsciência e a persistência destrutiva da mentira:

... a, longo prazo, o resultado mais certo da lavagem cerebral é uma curiosa espécie de cinismo - uma absoluta recusa a acreditar na verdade de qualquer coisa, por mais bem estabelecida que ela possa ser. Em outras palavras, o resultado de uma substituição coerente e total da verdade dos fatos por mentiras não é passarem estas a ser aceitas como verdade, $e$ a verdade ser difamada como mentira, porém um processo de destruição do sentido diante o qual nos orientamos no mundo real- incluindo-se entre os meio mentais para esse fim a categoria de oposição entre verdade e mentira... Esse é o motivo por que a mentira coerente, em termos metafóricos, arranca o chão de sob nossos pés, sem fornecer outra base em que nos postemos (p. 317-318, grifos nossos).

Ao analisar as estratégias utilizadas pelo autoritarismo, enquanto expressão de governos que impõe às sociedades humanas seu poder de forma coercitiva, Hannah Arendt fala dessa difusão oficial da mentira para justificar o arbítrio e a utilização da violência, identificada como legítima quando provém do Estado, para supostamente proteger a nação e seus cidadãos, para manipulá-los. Introduz, ainda, o conceito de "inimigo objetivo" para explicar a estratégia do autoritarismo para persuadir e angariar adeptos para sua arbitrariedade, a qual estigmatiza grupos ou parte da humanidade como portadores do mal. Usando desse dualismo maniqueísta, tais Estados autoritários colocam-se na posição de portadores e defensores do bem perante grupos ou povos que devem ser exterminados, porquanto ameaçadores da humanidade (Arendt, apud Lafer, 1979).

Talvez alguns poucos ainda creiam que as guerras acontecem, principalmente, por motivos políticos e religiosos. Modernamente, andam querendo nos convencer de que os "bem intencionados protetores da humanidade" envolvem-se em guerras para extirpar a ação maligna do terrorismo internacional. Muitos, porém, não ignoram que o carro chefe das guerras é o poder econômico, já que ela é uma rendosa forma de produzir dinheiro - primeira fonte de riqueza do mundo atual -, quer seja para refinar os investimentos no aprimoramento da tecnologia militar, quer seja para a venda de armas, ou até mesmo para sustentar as missões de socorro às populações vitimadas ou no pós-guerra, ou para a reconstrução das cidades destruídas (Chomsky, 2002; Pagman et al., 2003; Pilger, 2004; Polo, 2004).

Bauman (1998a), em seu livro "Modernidade e holocausto", analisa a permanência do holocausto e da barbárie no mundo de hoje, desmontando o mito de que, após "vencido" o fascismo de Hitler, estaríamos vivendo em uma "sociedade civilizada". Por meio do conceito de moralidade técnica, o autor desmonta essa farsa e revela as novas estratégias de encobrimento da crueldade que atravessam a vida dos homens, desde seus locais de trabalho, e que se espraiam pela sua vida em sociedade. Dialogando com Milgram, diz:

\begin{abstract}
... a crueldade não é cometida por indivíduos cruéis mas por homens e mulheres comuns tentando desempenhar bem suas tarefas ordinárias; e por sua descoberta de que a crueldade relaciona-se apenas secundariamente às características individuais dos que a cometem, mas de maneira muito forte mesmo à relação de autoridade e subordinação com nossa estrutura normal e cotidiana de poder e obediência (p. 181, grifos nossos).
\end{abstract}

Esse estudioso não procura no mercado em si as respostas para os desencontros dos homens na contemporaneidade. Ele examina a deteriorização das relações entre os homens apoiando-se na supremacia da tecnologia, que mediatiza as relações sociais, quer seja na parafernália impessoal da organização burocrática nas instituições ou a daquelas outras tecnologias que mantêm os homens à distância dos resultados de suas ações, conseqüentemente, sob o império da eliminação da culpa. Ele diz:

Numa burocracia as preocupações morais dos funcionários são afastadas do enfoque na situação angustiosa dos objetos da ação. São forçosamente desviados em outra direção - a tarefa a realizar e a excelência com a qual é realizada. Não importa tanto como passam e sentem os objetos da ação. Importa, no entanto, o nível de esperteza e eficiência com que o ator executa o que seus superiores ordenaram que executasse (Bauman, 1998b, p. 186-187, grifos nossos).

Além dessa obediência cega às regras que respondem às exigências da gestão empresarial, os espertos administradores passaram a utilizar-se da sofisticação tecnológica para justificar o controle arbitrário sobre os indivíduos. Vejamos: como com a maquinaria, a intencionalidade, o acompanhamento e o controle dos atos humanos não estão 
mais sob o seu domínio, porque entre o indivíduo e o produto de suas ações interpõe-se a tecnologia. Já não é mais seu cérebro que dá o comando nem suas mãos que executam as tarefas não lhes sendo, portanto, a compreensão da causalidade de seus atos perceptível, pois a técnica o substituiu. Assim, escapa aos indivíduos a compreensão das consequiências de seus atos. O controle é feito pelo "poder impessoal e anônimo da tecnologia", e o comando fabril aproveita muito bem essa circunstância ao deslocar a moralidade para a técnica, que passa a ser usada como uma poderosa estratégia de manipulação e opressão dos homens. É nesse sentido potencializador do encobrimento que a tecnologia vem sendo aproveitada como um poderoso instrumento de mentira. De fato, como os mais cépticos ou os mais sábios afirmam, é verdade que há uma minoria de homens poderosos que tem permissão social para violentar os demais.

Por outro lado, a manipulação social da distância permitida pela tecnologia e pela burocracia constrói a indiferença moral que oportuniza que a violência se espalhe na ordenação social sem que os homens se dêem conta do processo de mutilação de si e dos vínculos com os seus pares, e, menos ainda, desse sofrimento veiculado socialmente (Caniato \& Castro, 2002; Sawaia, 1999). Se focalizamos uma prática corriqueira na atualidade - a de apertar um simples botão que aciona poderosos mísseis, os quais, em poucos minutos, acertarão o alvo matando milhares de homens - a máxima atribuição de responsabilidade que vem sendo dada é a de admitir que houve um "erro técnico"(sic) e quem acionou o botão permanece em paz consigo. Assim diz Bauman (1998b):

quanto maior a distância física e psíquica da vítima, mais fácil era [é] ser cruel... A razão, pela qual a separação da vítima torna a crueldade mais fácil, parece psicologicamente óbvia: o executor é poupado da agonia de testemunhar o resultado de seus atos... O efeito da distância física e puramente psíquica é, portanto, ainda mais aumentado pela natureza coletiva da ação prejudicial... O opressor é membro de um grupo [e esta condição] deve ser vista como um tremendo fator a facilitar os atos de crueldade (p. 182-184, grifos nossos).

Não há dúvida de que a "massa obediente" de indivíduos está vivendo sob o suposto alívio da retirada da responsabilidade moral por seus atos, o que bloqueia nas suas mentes qualquer culpa verdadeira e reparadora. De fato, a crueldade só se agudiza porque conta com a participação dos sujeitos tornados cúmplices, não há duvidas; embora a subserviência desses homens seja um importante acionador dessa cumplicidade. É de causar indignação e até tristeza identificar "a facilidade com que a maioria das pessoas se encaixa no papel que requer crueldade ou pelo menos cegueira moral - bastando que este papel tenha sido devidamente fortalecido e legitimado pela autoridade superior" (Bauman, 1998a, p. 196, grifos nossos). Que cinismo servil é exigido dos homens para despir-se da responsabilidade sobre seus atos! É nesse embuste de si e do outro, nessa cumplicidade mórbida, que cada indivíduo banaliza e sustenta a violência social da burocracia e do manejo atual perverso da tecnologia, voltada contra o próprio homem que a criou, certamente com intenções utilitárias de tornar sua "vida mais fácil".

Como recuperar a capacidade dos homens de discernir erros de acertos se esses atributos morais perderam socialmente suas diferenciações intrínsecas e se, cada vez mais, a impunidade alastra-se na sociedade, referendando essa equalização (Caniato, 1999)? Como fazer com que os homens confiem na solidariedade de seus parceiros e se desvencilhem da violência e da desconfiança que penetrou na relação entre eles? Como os homens conseguirão recuperar a integridade de suas potencialidades psicossociais que lhes permita assumir suas funções de sujeitos $d a$ cultura?

\section{A Resistência dos Homens à Procura da Verdade Emancipatória}

Sintetizando: a violência social, a manipulação do indivíduo, a indústria cultural, a suspeição entre os indivíduos, a vigilância e o controle sociais, a cumplicidade mórbida subjetiva, o esfacelamento das tradições, as banalizações do mal, da injustiça social, do sofrimento e da dor e a confusão nas leis que regem a ordem social são alguns dos atributos da PERVERSIDADE DA MENTIRA que produzem SOFRIMENTO PSÍQUICO e convivem de mãos dadas para destruir a autonomia cultural dos sujeitos. A MENTIRA vem, falsamente, mistificando a MORTE que se espraia no planeta Terra, DISFARÇADA sob formas democráticas de governo, de políticas públicas, ditas equalizadoras, de justiça social e direitos humanos.

Ouçamos o apelo à RESISTÊNCIA na carta, em nome do povo cubano, dirigida por Fidel Castro (2004) ao senhor Bush:

Tudo que se escreve sobre direitos humanos em seu mundo e no de seus aliados que compartilham o saque do planeta, é uma COLOSSAL MENTIRA. Milhares de milhões de seres humanos vivem com fome, sem alimentos suficientes, medicinas, roupas, sapatos, casas, em condições subhumanas, sem os mínimos conhecimentos e suficiente informação para compreender sua tragédia e do mundo que vivem (grifos nossos).

A saída transformadora dessa barbárie e do caos na cultura só existirá se pudermos RESISTIR e sustentar a esperança utópica de uma vida melhor, pois, como diz Hannah Arendt (2002):

a verdade, posto que impotente é sempre perdedora em choque frontal com o poder, possui uma força 
que lhe é própria: o que quer que possam idear aqueles que detêm o poder, eles são incapazes de descobrir ou excogitar substituto viável para ela. A persuasão e a violência podem destruir a verdade, mas não substituí-la (p. 320, grifos nossos).

Mais animador ainda, embora paradoxalmente sob o risco da própria vida, verificamos no seguinte dizer:

(O)[o]nde todos mentem a cerca de tudo que é importante, aquele que conta a verdade começou a agir; quer o saiba ou não, ele se comprometeu também com os negócios políticos, pois, na improvável eventualidade de que sobreviva, terá dado um primeiro passo para a transformação do mundo (Arendt, 2002, p. 310-311, grifos nossos).

\section{Notas}

1 Esse parágrafo está construído com auxílio do conceito de "pensamento reflexivo" de Theodor Adorno e Horkheimer (1985).

2 Fazemos referência ao exame da simbiose e das dificuldades de individuação entre gêmeos idênticos que está narrada no filme "Gêmeos mórbida semelhança" cujo diretor é David Cronenberg.

\section{Referências}

Abeche, R. P. C. (2003). Por trás das câmeras ocultas a subjetividade desvanece. Tese de Doutorado não-publicada, Faculdade de Filosofia e Ciências da Religião, Universidade Metodista de São Paulo, SP.

Adorno, T. W. (1986a). A indústria cultural. In F. Fernandes (Ed.), Theodor W. Adorno: Vol. 54. Grandes Cientistas Sociais (pp. 92-99). São Paulo, SP: Ática.

Adorno, T. W. (1986b). A Educação após Auschwitz. In F. Fernandes (Ed.), Theodor W. Adorno: Vol. 54. Grandes Cientistas Sociais (pp. 3-45). São Paulo, SP: Ática.

Adorno, T. W. (1993). Mínima moralia: Reflexões a partir da vida danificada [Mínima Moralia Suhrkamp Verlag] (2. ed., L. E. Bicca, Trad.). São Paulo, SP: Ática.

Adorno, T. W. (1995). Educação e emancipação [Erziehung zur Mündgkeit, Vorträge und Gespräche mit Hellmut] (L. M. Wolfgang, Trans.). Rio de Janeiro, RJ: Paz e Terra.

Adorno, T. W., \& Horkheimer, M. (1985). Dialética do esclarecimento: Fragmentos filosóficos [Dialektik der Aufklarüng - Philosophische Fragmente] (G. A. Almeida, Trad.). Rio de Janeiro, RJ: Jorge Zahar.

Aidé, M. A. K. (2002, dez.). Me engana que eu gosto: A tirania da sedução. Estudos de Psicanálise - CBP, 25, 67-77.

Arendt, H. (1973). A mentira política: Considerações sobre os documentos do Pentágono. In Crises da República [Crisis of the Republic] (pp. 9-48, J. Volkmasnn, Trad.). São Paulo, SP: Perspectiva.

Arendt, H. (2000). Eichmann em Jerusalém: Um relato sobre a banalidade do mal [Eichmann in Jerusalem: A Report on the Banality of Evil] (J. R. Siqueira, Trad.). São Paulo, SP: Companhia das Letras.

Arendt, H. (2002). Verdade e política. In Entre o passado e o futuro [Between Past and Future] (5. ed., pp. 282-325, M. W. B. Almeida, Trad.). São Paulo, SP: Perspectiva.
Arreguy, M. E., \& Garcia, C. A. (2002). A ausência de ciúme: Notas sobre o consumo do amor. In Congresso Psicanálise, Poder e Transgressão. São Leopoldo, RS. Retirado em 14 nov. 2006, de http://www.cprs.com.br/viforum/diversos/marilia_etienne_arreguy.rtf

Barbarini, N. (2001). Trabalho bancário e reestruturação produtiva: Implicações no psiquismo dos trabalhadores. Dissertação de Mestrado não-publicada, Instituto de Psicologia, Universidade Federal do Rio Grande do Sul, Porto Alegre, RS.

Bauman,Z. (1998a). A ética da obediência (lendo Milgran). In Modernidade e holocausto [Modernity and Holocaust] (pp. 178-196, M. Penchel, Trad.). Rio de Janeiro, RJ: Jorge Zahar.

Bauman, Z. (1998b). Para uma teoria sociológica da moralidade. In Modernidade e holocausto [Modernity and Holocaust] (pp. 197-229, M. Penchel, Trad.). Rio de Janeiro, RJ: Jorge Zahar.

Bauman, Z. (1999). Turistas e vagabundos. In Globalização: As consequiências humanas [Globalization:The Human Consequences] (pp. 85-110, M. Penchel, Trad.). Rio de Janeiro, RJ: Jorge Zahar.

Beinstein, J. (2000, abr.). La gran mutación del capitalismo. Narcomafias, centro y periferia. Le Monde Diplomatique - El Diplo, 10.

Brie, C. de (2000a, abr.). No inferno dos paraísos fiscais. Retirado em 02 maio 2004, de http://www.diplo.com.br/aberto/0004/04a.htm

Brie, C. de (2000b, abr.). Onde as máfias, as transnacionais e os governos se encontram. Retirado em 16 abr. 2004, de http:// www.diplo.com.br/aberto/0004/04.htm

Caniato, A. M. P. (1999a, maio/dez.). A impunidade na sociedade e no Direito: Implicações psicossociais. Psicologia-UFF, 11(2-3), 9-26.

Caniato, A. M. P. (1999b) A subjetividade na contemporaneidade: Da estandartização dos indivíduos ao personalismo narcísico. In A. F. Silveira (Eds.), Cidadania e participação social (pp. 13-29). Porto Alegre, RS: Abrapsosul.

Caniato, A. M. P. (2000). Da violência no ethos cultural autoritário da contemporaneidade e do sofrimento psicossocial. PSI-Revista de Psicologia Social e Institucional, 2(2), 197-215.

Caniato, A. M. P. (2003). Da subjetividade sob sofrimento narcísico numa cultura da banalidade do mal. Retirado em 01 maio 2004, de http://www.estadosgerais.org/mundial_rj/port/trabalhos/ 5c_caniato_18050803_port.htm

Caniato, A. M. P., \& Castro, M. A. (2002). "Ficar com”: Uma das expressões do sofrimento psicossocial. Mimeo.

Caniato, A. M. P. P., \& Castro, M.A. (2003). As matrizes psicossociais do sofrimento humano. Retirado de http://www.estadosgerais.org/ terceiro_encontro/castrocaniato-matrizes.shtml

Caniato, A. M. P., \& Nascimento, M. L. (2006). A vigilância na contemporaneidade: Significados do vigiar e suas implicações na subjetividade. Mimeo.

Carone, I. (2004). Da origem aristotélica aos nossos dias. Mimeo.

Castro, F. (2004, 16 maio). Carta do povo cubano à Bush: "Salve César, os que vão morrer te saúdam". Diário Vermelho [Versão eletrônica].

Chaú, M. (1993). Conformismo e resistência (5. ed.). São Paulo, SP: Brasiliense.

Chomsky, N. (2002). 11 de setembro (L. A. Aguiar, Trad.). Rio de Janeiro, RJ: Bertrand Brasil.

Cohn, G. (1986). Adorno e a Teoria Crítica da Sociedade. In F. Fernandes (Ed.), Theodor W. Adorno: Vol. 54. Grandes Cientistas Sociais (pp. 7-30). São Paulo, SP: Ática.

Ciombra, C. (2001). Operação Rio: o mito das classes perigosas. Um estudo sobre a violência urbana, a mídia impressa e os discursos de segurança pública. Rio de Janeiro, RJ: Oficina do Autor. 
Dejours, C. (2000). A banalização da injustiça social [Souffrance en France:la banalization de l'injustice sociale] (3. ed., L. A. Monjardim, Trad.). Rio de Janeiro, RJ: Editora da Fundação Getúlio Vargas.

Di Loretto, O. D. M. (1997). Em defesa do meu direito de ser triste. Psicologia em Estudo, 2(3), 1- 52.

Dufour, D.-R. (2001). As angústias do indivíduo-sujeito. Retirado em 10 maio 2001, dehttp://www.diplo.com.br/aberto/anteriores.htm

Freud, S. (1948). Psicologia de las masas. In S. Freud: Vol. 1. Obras Completas (pp. 1119-1157). Madrid, España: Biblioteca Nueva.

Freud, S. (1981). El malestar en la cultura. In S. Freud: Vol. 3. Obras Completas (pp. 3018-3067). Madrid, España: Biblioteca Nueva.

Green, A. (1988). Narcisismo de vida e narcisismo de morte (C. Berliner, Trad.). São Paulo, SP: Escuta.

Guinsberg, E. (2001). La salud mental en el neoliberalismo. Ciudad de México, Mexico: Plaza y Valdés.

Kehl, M. R. (2002). Visibilidade e espetáculo. In III Congresso dos Estados Gerais da Psicanálise. Buenos Aires, Argentina. Retirado de http://estadosgerais.org/terceiro_encontro/kehl-espetaculo.stml

Kornbluh, P. (2004, 3 abr.). Brasil, documentos desclassificados lançam luz sobre o papel do governo americano no golpe de $1^{\circ}$ de Abril de 1964. Retirado em 10 abr. 2004, de http://www.resistir. info/brasil/golpe_64.html.

Lafer, C. (1979). O anti-semitismo, os judeus e o mundo moderno. In H. Arendt. Pensamento, persuasão e poder: Vol. 35. O Mundo Hoje (pp. 39-55). Rio de Janeiro, RJ: Paz e Terra.

Lipowetsky, G. A. A. (1983). A era do vazio: Ensaio sobre o individualismo contemporâneo (M. S. Pereira \&A. L. Pereira, Trads.). Lisboa, Portugal: Relógio DÁgua.

Lowen, A. (1983). Narcisismo: Negação do verdadeiro self. (A. Cabral, Trad.). São Paulo, SP: Cultrix.

Lucchesi, I. (2002, 04 ago.). Mídia e sedução sem encantamento. Rio de Janeiro, RJ: Observatório da Imprensa. Retirado em 04 set. 2002, de http://www.observatoriodaimprensa.com.br/artigos/ jd060320024

Maia, M. S. (2001). Um tapete vermelho para a angústia: A clínica psicanalítica e contemporaneidade. Revista de Psicanálise-Percurso, 14(27), 67-76.

Mariotti, H. (2000, 20 out.). A era da avareza: A concentração de renda como patologia bio-psico-social. Trabalho apresentado na Associação Pala Athena. Ciclo de Estudos: As dores da alma. São Paulo, SP.

Martin, H. P., \& Schumann, H. (1999). Armadilha da globalização: $O$ assalto à democracia e ao bem estar social (5. ed) São Paulo, SP: Globo.

Martín-Baró, I. (1987). El latino indolente. Carácter ideológico del fatalismo latinoamericano. In M. Montero (Ed.), Psicologia Política Latinoamericana (pp. 135-162). Caracas, Venezuela: Panapo.

Odália, N. (1983). O que é violência: Vol. 85. Primeiros Passos. Brasiliense, São Paulo, SP: Brasiliense.

Ortega, F. (2002). Da ascese à bio-ascese, ou do corpo submetido à submissão ao corpo. In M. Rago \& V. A. Neto (Eds.), Imagens de Foucault e Deleuze: Ressonâncias nietzschianas (pp. 1-24). São Paulo, SP: DP\&A.

Pagman, R., Simionato, M., \& Mena, F. (2003, 23 jun.). Território inimigo. Folha de São Paulo, p. 06-08.

Pilger, J. (2004). O ataque à BBC. A verdade oficial é uma mentira. Retirado em 10 abr. 2004, de http://resistir. info/europa/pilger_ bbc_09fev04.html

Polo, H. (2004, 12 abr.). Estados Unidos, sibildos de serpiente. Correio de Información ATTAC - "El Grano de Arena", 235. Retirado em 14 abr. 2004, de http://attac.org/attaccinfoes/attacinfo235.zip

Quesada, R. A (2004, 25 mar.). La mentira y la prensa. La resurreción de Jacqueline y otros fantasmas. Retirado em 10 abr. 2004, de http://www.rebelion.org/imperio/o40325ra.htm

Sawaia, B. S. (1999). O sofrimento ético-político como categoria de análise da dialética exclusão/inclusão. In B. B. Sawaia (Ed.), As artimanhas da exclusão: Análise psicossocial e ética da desigualdade social (pp. 97-118). Petrópolis, RJ: Vozes.

Sennett, R. (2001). Flexível. In Corrosão do caráter: Conseqüências pessoais do trabalho no novo capitalismo [Corrosion of character] (pp. 51-73). Rio de Janeiro, RJ: Record.

Stengel, M. (2003) Obsceno é falar de amor. As relações afetivas dos adolescentes. Belo Horizonte, MG: Editora da Pontifícia Universidade Católica de Minas Gerais.

Teixeira, C. A. (2002, 01 abr.). O dia da mentira. Retirado em 02 maio 2004, de http://www.iis.com.br/ cat/infoetc/538.htm

Ulloa, F. O. (2001a). Sociedad y crueldad: notas preliminares. Retiradoem 21 set. 2002, dehttp://www.etatsgeneraux-psychanalyse.net/ archives/texte171.html

Ulloa, F. O. (2001b). Una perspectiva psicoanalitica de la crueldad. Retirado em 21 set. 2002, de http://www.etatsgeneraux-psychanalyse.net/archives/texte90.html

Universidade Federal de Goiás. (2004). 01 de abril-Dia da mentira. Retirado em 02 maio 2004, de http://www.ufg.br/datas_comemorativas/abril/01_abril_mentira.html

Ventura, Z. (1998). Mal secreto: Inveja. Rio de Janeiro, RJ: Objetiva. Vieira, L. V. (2003, 17 mar.). O barato da dor. Época, 252.

Angela Caniato é Psicóloga Clínica de base psicanalítica. Endereço para correspondência: Rua Joaquim Nabuco, 1496, Maringá, PR, 87 014-100. ampicani@onda.com.br

\section{A banalização da mentira como uma das perversões da sociedade contemporânea e sua internalização como destrutividade psíquica}

Angela Maria Pires Caniato

Recebido: 30/10/2006

$1^{\mathrm{a}}$ revisão: $17 / 01 / 2007$

Aceite final: 31/05/2007 